\title{
ON THE NEED FOR A GLOBAL ENGINEERING INITIATIVE TO MITIGATE CLIMATE CHANGE
}

\author{
MAX F. PLATZER \\ AeroHydro Research \& Technology Associates, Pebble Beach, California USA.
}

\begin{abstract}
There is growing scientific evidence that the continued emission of greenhouse gases will eventually lead to catastrophic irreversible climate change and that, therefore, a global effort needs to be started to transition to a fully renewable economy. In this article, the engineering challenges of converting to emission-free power generation are reviewed and the feasibility of two proposed solutions, i.e. the 'wind-water-solar' and the 'energy ship' proposals, are discussed. It is concluded that a well-conceived and executed engineering effort needs to be initiated and guided by a Global Engineering Council for the purpose of examining and ranking various proposals and making specific recommendations.

Keywords: climate change, climate mitigation, emission-free power generation, renewable energy, wind power
\end{abstract}

\section{INTRODUCTION}

Ever since Wallace Broecker [1] predicted in 1975 that Earth's then natural cooling period would soon no longer be able to neutralize the heating effect from trapped carbon dioxide gas in the atmosphere, the research conducted for the past 40 years has clearly established the deleterious effect of the burning of carbon-based fuels on the environment. The most recent report issued by the Intergovernmental Panel on Climate Change (IPCC) [2] provides a comprehensive overview of the impact further greenhouse gas emissions will have on the agricultural production, global fisheries, ocean acidification, sea-level rise, and land use that will affect the people in various parts of the globe in different ways. The academies of science of various countries agree with the IPCC warnings that continued global warming starts to endanger future generations because a tipping point of irreversible climate change will eventually be reached in the near future. For this reason, Hansen et al. [3] emphasize the need for a reduction in carbon emissions to protect future generations. They point out that till 2012 approximately $370 \mathrm{GtC}$ (gigatons of carbon) have been emitted and they warn that cumulative emissions of $1000 \mathrm{GtC}$ will lead to a warming of $3-4^{\circ} \mathrm{C}$ with disastrous consequences. Therefore, they stipulate to start cutting global carbon dioxide emissions at a rate of $15 \%$ per year no later than 2020.

Hence, a consensus has been reached in the scientific community that the debate about the need for global emission reductions is over. It is the purpose of this article to stimulate the beginning of a debate about effective engineering methods to mitigate climate change.

\section{THE ENGINEERING CHALLENGE OF EFFECTIVE CLIMATE CHANGE MITIGATION}

Since approximately $80 \%$ of the total global energy production is based on the burning of coal, oil or natural gas, the task of converting to renewable energy production is a huge task indeed. It is, therefore, not surprising that the authors of most reports and books about this subject either state explicitly that a full conversion cannot be accomplished before the end of the century or that a substantial contribution will have to come from expanded nuclear power production. MacKay [4] presented a quite comprehensive analysis of the options available to 
the United Kingdom. He concluded that a full conversion to renewable energy production is only possible by importing electric power from North Africa and the Middle East. The power or energy densities and the usable land available within the United Kingdom are simply too small to enable a full transition. The same conclusion applies to the whole of Europe. For this reason, the 'Desertec Initiative' was launched a decade ago to place concentrating solar power plants in North Africa and to transmit the electric power by means of special high-voltage direct current transmission lines to the European continent. This initiative had to be abandoned due to the technical difficulties and the political uncertainties that had to be confronted. In 2009, Hansen [5] advocated 'an urgent, substantial research and development program on fourth-generation nuclear power, so that we have at least one viable option in the likely event that efficiency and renewables cannot provide all needed energy'. In 2008, Inslee and Hendricks [6] called for an Apollo energy program to ignite America's clean energy economy, but stressed that 'there are no silver bullets'.

\section{PROBLEM STATEMENT}

Any debate about the feasibility of engineering solutions to the climate change crisis has to start with a specific statement of the problem which is to be addressed. The total global energy or power production is approximately $150,000 \mathrm{TWh}$ or $16 \mathrm{TW}$, respectively. Therefore, 120,000 TWh or $13 \mathrm{TW}$ need to be switched from fossil-based to renewable energy/ power production, starting no later than 2020. This will require a replacement rate of 12,000, 6,000 , or 3,000 TWh per year to accomplish a full transition in 10,20 , or 30 years. This global energy/power replacement requirement can then be quantified for each individual country to achieve complete transparency and accountability. This problem statement implies the specification of technologies which are readily available for application within the specified execution period of 10, 20, or 30 years. Therefore, it will be difficult to propose innovative 'geo-engineering' solutions, which require unspecified amounts of research and development time and money.

\section{PROPOSED PROBLEM SOLUTIONS}

It appears that only three proposals have been published to meet the goal of global climate mitigation within 30 years.

In 2009, Jacobson and Delucchi [7] presented a plan for a sustainable future by proposing to satisfy the global energy demand from wind, water, and solar power by 2030 . To achieve this goal, they proposed the installation of 490,000 tidal turbines of $1 \mathrm{MW}$ output per turbine, 5,350 geothermal plants of $100 \mathrm{MW}$ output per plant, 900 hydroelectric plants of $1.3 \mathrm{GW}$ output per plant, 3,800,000 wind turbines of $5 \mathrm{MW}$ output per turbine, 720,000 wave converters of $0.75 \mathrm{MW}$ per converter, 1,700 million $3 \mathrm{~kW}$ roof top photovoltaic systems, 49,000 concentrating solar power plants of $300 \mathrm{MW}$ per plant, and 40,000 photovoltaic power plants of $300 \mathrm{MW}$ per plant. They estimated the overall construction cost of such a wind-watersolar (WWS) power generation system to require an investment in the order of $\$ 100$ trillion worldwide.

In 2009, Platzer and Sarigul-Klijn [8] proposed to exploit the wind power available over certain ocean areas by operating large sailing ships which can produce about 2 or $3 \mathrm{MW}$ of electric power to be fed into electrolyzers for conversion of sea water into hydrogen and oxygen. In the same year, Kim and Park [9] proposed to use parawing-driven large ships to take advantage of higher altitude winds than possible with sailing ships. A major advantage of this 'energy ship concept' is the conversion of wind power into storable energy in the form 


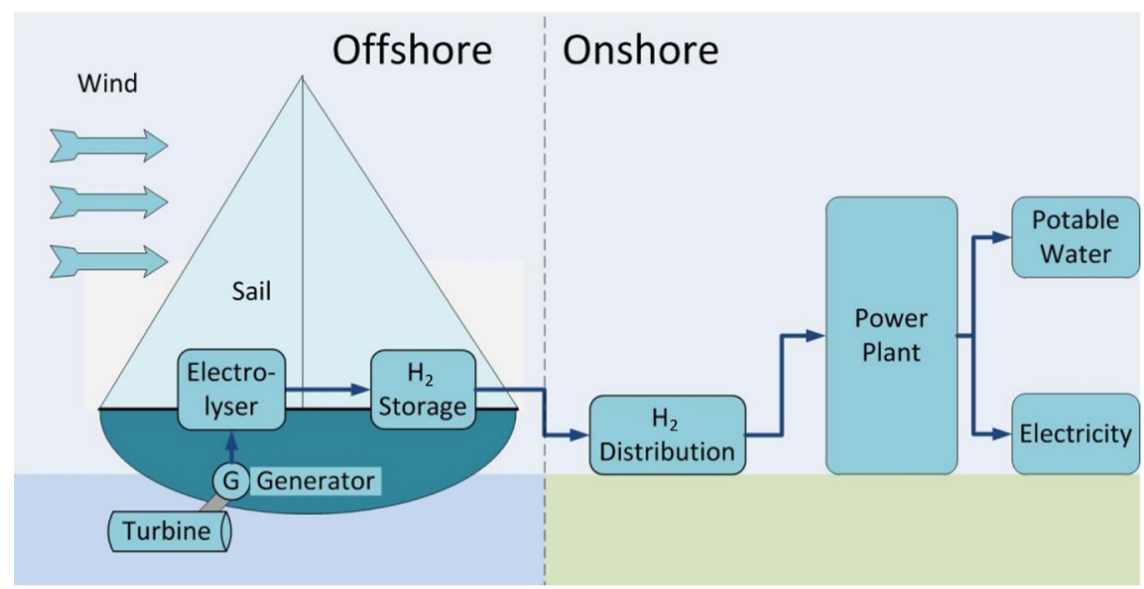

Figure 1: Overall system scheme of the energy ship conversion chain.

of high-pressure hydrogen gas or liquid hydrogen. Another advantage is the much higher capacity factor available to sailing ships operating in wind-rich ocean areas as compared to land or off-shore based wind turbines. These two features make it possible to implement the 'power-to-gas' concept whereby the intermittency problem of conventional wind and solar power plants can be overcome by making hydrogen available on demand. A further advantage is the ability to operate the energy ships in international waters so that any country can send its fleet of energy ships to these areas without having to ask for permission. Therefore, the legal obstacles encountered by renewable energy development projects within a country's national boundaries are avoided.

The basic energy ship concept is shown in Fig. 1. The hydrogen tanks are periodically transported back to shore where the hydrogen is used for heating and cooking purposes, as transportation fuel for hydrogen fuel cell vehicles or for reconversion into electricity. Further information about the energy ship concept was developed by Platzer et al. [10-13] and Kim and Park [14].

In 2012, Watson and Frank [15] proposed a 15-year roadmap towards complete energy sustainability, using the example of the state of Hawaii. They suggested that the intermittent energy supply problem caused by renewable energy sources such as solar and wind can be solved by using the ground transportation sector as a means of storing energy. Switching to electric vehicles and extended-range vehicles (plug-in hybrids), their vehicle batteries become available as an energy storage system, which can supply energy both for transportation and stationary use by means of bidirectional chargers (defined as a charger that can take alternating current electric energy and charge a direct current battery and reconvert the stored direct current energy back into synchronized alternating current energy).

\section{TECHNICAL FEASIBILITY ASSESSMENT OF THE PROPOSED SOLUTIONS}

The Jacobson-Delucchi WWS approach requires the construction and operation of millions of land or off-shore wind turbines and roof-top photovoltaic systems, hundreds of thousands of tidal turbines and thousands of concentrating solar power plants. The power output of the WWS system can be expected to be far below the theoretically possible output because of the constraints encountered in practice, as described quite thoroughly by MacKay [4] for the 
United Kingdom. The low wind and solar power densities near most high-population-density areas diverts the wind and solar power generators into remote areas with greater power densities at the cost of requiring the construction of new transmission lines. Furthermore, the power supply fluctuations inherent in the WWS system require the availability of an effective energy storage system. Nevertheless, the WWS proposal represents the first attempt at quantifying the effort needed to develop a global renewable energy production system.

The energy ship proposal aims to overcome the WWS constraints by opening up a huge new energy reservoir in the form of strong winds over large ocean areas and by converting the ocean wind power into storable energy in the form of hydrogen. The number of ships required is again many millions. If one ship delivers $3 \mathrm{MW}$ to the electrolyzer, only $1 \mathrm{MW}$ can be expected to become available after shipment of the hydrogen back to shore and reconversion to electric power. Therefore, approximately 500,000 ships are required to produce $0.5 \mathrm{TW}$, leading to $15 \mathrm{TW}$ if every year an additional half a million ships are added for 30 years. This number can be reduced by an order of magnitude if, say, 10 ships are coupled together into one convoy.

The Watson-Frank proposal aims at the provision of an effective energy storage system by using the batteries of the many millions of vehicles currently in use. The exploitation of this energy reservoir becomes particularly attractive when the larger batteries needed for electric or hybrid plug-in vehicles are used.

\section{GESTATION PERIOD OF NEW TECHNOLOGIES}

The history of past technology developments may provide encouraging guidance for the future. The first flight of the Wright brothers in 1903 led to the operation of well over 200,000 airplanes in only 15 years by the end of World War I. The first flight of a small jet powered German airplane in 1939 led to the introduction of the first commercial jet-propelled aircraft, the British Comet 1 aircraft, only 13 years later. The first flight of the supersonic V-2 rocket in 1942 led to the launch of the first satellite only 15 years later in 1957 and to the flight of two astronauts to the moon only 12 years later in 1969. It is, therefore, tempting to suggest that the introduction of a new global energy production system should require less than 30 years.

From a purely technical point of view, such an introduction can be implemented only if a renewable energy supply can be identified by ranking all possible renewable energy sources. Figure 2 shows that there are vast ocean areas near the Arctic and Antarctica that have wind speeds and wind power densities superior to those available on and near land. Hence, both in terms of quantity and quality, ocean wind power ranks highest among possible renewable energy sources. As explained earlier and in References [8-14], the energy ship technology requires no new technology elements although the combination of sailing ships with hydrokinetic turbines, electrolyzers, compressors, and hydrogen tanks represents a new technology. This indicates that the gestation time for this new system whose technology elements are already well known is likely to be shorter than the gestation time of the entirely new systems developed in the last century.

\section{IMPEDIMENTS TO INTRODUCTION OF A GLOBAL RENEWABLE ENERGY PRODUCTION SYSTEM}

Unfortunately, the mere technical feasibility of a new system stimulates its development only if there is a strong demand. The rapid development and use of the newly invented airplane was stimulated by the rapid recognition of its military usefulness. Indeed, after World War I 

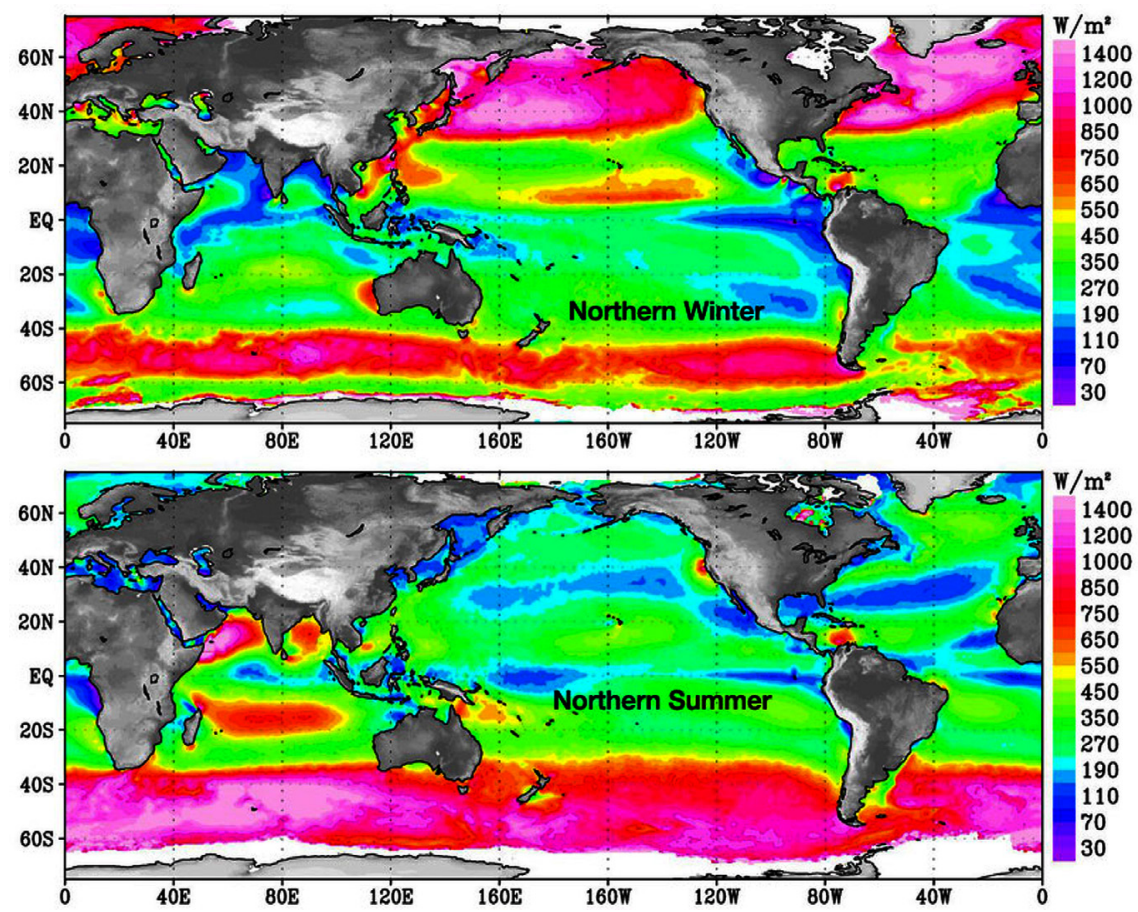

Figure 2: Global ocean windpower distribution. (Source: NASA)

there was no obvious demand beyond its use as a mail carrier and the momentum for new developments was only regained during World War II. Similarly, the rocket developments during World War II and during the Cold War were stimulated entirely by military considerations. Although nominally a civilian program, the Apollo program was conceived and executed in response to the Soviet challenge.

It is probably correct to say that 20th century innovative engineering made it possible to 'conquer space and time'. By the third quarter of the last century, it became possible to travel to any point on the globe within a day and by the end of the century affordable instant communication became commonplace. These amazing developments were 'fear-driven' [16] without concern for economic returns. It therefore appears that there are two phases in the introduction of new technologies, an initial 'fear-driven' tax-payer funded phase, followed by a 'greed-driven' phase that leads to system optimization and economic returns by eliminating economically less competitive systems.

The crucial question for the near future, therefore, is whether effective global climate mitigation can be accomplished by limiting the search for solutions to technologies that are economically viable from the very start. A very recent answer to this question was provided by the two Google engineers Koningstein and Fork [17] who were tasked by the Google Corporation to look for reliable zero-carbon energy sources so cheap that the operators of power plants and industrial facilities have an economic incentive to switch to renewable power production. In particular, Google was looking for a technology that would change the economic rules of the game by producing not just electricity but also fertilizer, fuel, or desalinated water. They came to the conclusion that no such disruptive technology is in sight. Quoting from their paper they state: 'Incremental improvements to existing technologies 
aren't enough; we need something truly disruptive to reverse climate change. What then is the energy technology that can meet the challenging cost targets? We don't have the answers.'

\section{NEED FOR A GLOBAL ENGINEERING COUNCIL}

The Google Corporation analysis suggests that the time has come to initiate a process similar to the process pursued by the IPCC to arrive at a consensus concerning climate change. The various governments and the general public need to hear from the global engineering community what actions are required to avert irreversible climate change. Therefore a 'Global Engineering Council' needs to be formed to evaluate the options which have already been proposed to transition to renewable power generation within 10, 20, or 30 years, to seek new options and to rank all options according to feasibility, technical effort, and cost. An important outcome of the deliberations of this 'Global Engineering Council', with members from all major engineering societies, should be a characterization of the type of effort that is required, namely whether only well-coordinated government programs have any prospect for success or whether investment-oriented programs are adequate. The assessment and recommendations of this Global Engineering Council should make it possible to mobilize governments and citizens to initiate a global climate mitigation program.

\section{NEED FOR UNITED GLOBAL ACTION TO MITIGATE CLIMATE CHANGE}

In his book 'Collapse - How Societies Choose to Fail or Succeed' Jared Diamond [18] presents an instructive history of the collapse of past civilizations and concludes that the impoverishment or outright demise of past civilizations can be traced to foolish leaders who embroiled them in expensive wars, cared only about staying in power, and did not pay attention to problems at home. Indeed, the two world wars provide incontrovertible evidence that even the most highly developed civilizations are capable of self-destructive actions. There is therefore reason to be pessimistic about the future. However, Diamond is certainly correct in pointing out that the past may not be a good predictor of the future for the following reasons:

1. Our planet provides abundant renewable resources to power the world economy.

2. The technologies are available to exploit the global renewable energy resources.

3. The global communication systems make it possible to mobilize the world community into action.

As shown in Fig. 2, there cannot be any doubt that there is an abundant supply of ocean wind power if one acknowledges that the technology, shown in Fig. 1, makes it possible to convert this wind power into storable energy. However, it is necessary to take a global instead of a nationalistic point of view, meaning that the search for renewable resources does not have to stop at the national borders. Furthermore, it is necessary to abandon the notion that power generation is necessarily limited to non-moving power plants. Therefore, lack of technology is unlikely to become a barrier to transitioning to a renewable energy economy. Instead, inability to understand the physics of climate change, lack of a sense of urgency, and concerns about the cost and magnitude of the task are the more likely factors which may prevent effective and timely climate change mitigation.

Fortunately, there is a growing awareness that human-induced climate change is already affecting the living standards of most citizens in the world. For example, in June 2014 the former mayor of New York, Michael R. Bloomberg, the former secretary of the United States Treasury, Henry M. Paulson Jr., and the founder of the venture capital investment firm 
Farallon Capital Management, Thomas F. Steyer, endorsed a report [19] on the economic risks faced by the United States if climate change continues unabated. This report makes it clear that the damage caused by continuing climate change needs to be quantified and taken into account when the financial returns expected from renewable energy projects are estimated. Since the Google Corporation sees no economic incentive for renewable power generation [17], the endorsement of this report by three highly successful private enterprise tycoons raises the important question about the type of financing (taxpayer or private funding) needed to initiate a global climate change mitigation program.

The debate of the technical and economic aspects of this program requires the involvement not only of the engineering and economics community but also of many other segments of the world population, especially the young generation who has the greatest stake in the success of this initiative. It is fortunate that the means of instant effective communication are available to expose misconceptions, to influence the debate and to demand effective action.

\section{SUMMARY}

The global scientific community has reached a consensus that human-induced climate change needs to be mitigated within 30 years to prevent major adverse effects. The transition to an emission-free economy will require a well conceived and executed engineering effort, which needs to be initiated and guided by a Global Engineering Council for the purpose of examining and ranking various proposals and making specific recommendations. The 'wind-watersolar' and an 'energy ship' proposals, discussed in this article, can serve as starting points for a comprehensive debate of the technical and financial feasibility of achieving a fully renewable energy economy by no later than 2050 .

\section{REFERENCES}

[1] Broecker, W.S., Climate change: are we on the brink of pronounced global warming? Science, 189(4201), pp. 460-463, 1975. doi: http://dx.doi.org/10.1126/ science. 189.4201 .460

[2] Intergovernmental Panel on Climate Change (IPCC), Fifth Assessment Report, IPCC, 2014.

[3] Hansen, J., Kharecha, P., Sato, M., Masson-Delmotte, V., Ackerman, F., Beerling, D.J., Hearty, P.J., Hoegh-Guldberg, O., Hsu, S.L., Parmesan, C., Rockstrom, J., Rohling, E.J., Sachs, J. \& Zachos, J.C., Assessing dangerous climate change: required reduction of carbon emissions to protect young people, future generations and nature. PLoS One, 8(12), e81648. doi: 10.1371/journal.pone.0081648

[4] MacKay, D.J.C., Sustainable Energy - Without the Hot Air, UIT Cambridge Ltd: Cambridge, England, 2009.

[5] Hansen, J., Storms of My Grandchidren, Bloomsbury: New York, 2009.

[6] Inslee, J. \& Hendricks, B., Apollo's Fire, Igniting America's Clean Energy Economy, Island Press: Washington, DC, 2008.

[7] Jacobson, M.Z. \& Delucchi, M.A., A path to sustainable energy by 2030. Scientific American, 301(5), pp. 58-65, 2009. doi: http://dx.doi.org/10.1038/scientificamerican1109-58

[8] Platzer, M.F. \& Sarigul-Klijn, N., A novel approach to extract power from free-flowing water and high-altitude jet streams, ASME Energy Sustainability Conference, San Francisco, CA, 2009. doi: http://dx.doi.org/10.1115/es2009-90146 
[9] Kim, J. \& Park, C., Wind power generation with a parawing on ships, a proposal. Journal of Energy, 35(3), pp. 1425-1432, 2010. doi: http://dx.doi.org/10.1016/j. energy.2009.11.027

[10] Platzer, M.F. \& Sarigul-Klijn, N., Aerohydronautical Power Engineering - Is It the Key to Abundant Renewable Energy and Potable Water? University Readers: San Diego, CA, 2012.

[11] Platzer, M.F., Lennie, M. \& Vogt, D.M., Analysis of the conversion of ocean wind power into hydrogen. Proc. World Renewable Energy Congress, Perth, Australia, July 2013.

[12] Platzer, M.F., Sarigul-Klijn, N., Young, J., Ashraf, M.A. \& Lai, J.C.S., Renewable hydrogen production using sailing ships. Journal of Energy Resources Technology, 136(2), pp. 021203-1 to 5, 2014.

[13] Holl, M., Platzer, M.F. \& Pelz, P., Optimal energy systems design applied to an innovative ocean-wind energy converter. WIT Transactions on Ecology and the Environment, 193, 2015.

[14] Kim, J. \& Park, C., Economy of hydrogen production by parafoil-pulled ships. Journal of Energy and Power Sources, 1(1), pp. 9-16, 2014.

[15] Watson, S. \& Frank, A., A fifteen year roadmap toward complete energy sustainability. UC Davis Institute of Transportation Studies Research Report UCD-ITS-RR-12-35, January 2012.

[16] Platzer, M.F., Is there an engineering approach to transition to a sustainable hydrogen economy? WIT Transactions on Ecology and the Environment, 193, 2015.

[17] Koningstein, R. \& Fork, D., What it would really take to reverse climate change. IEEE Spectrum, Posted 18 November 2014.

[18] Diamond, J., Collapse, Penguin Books, 2005.

[19] A Climate Risk Assessment for the United States, Risky Business, June 2014. 